\title{
PROPRIEDADES FAMILIARES MULTIFUNCIONAIS NO MEIO RURAL NOS DISTRITOS ARROIO GRANDE E SÃO VALENTIM - SANTA MARIA/RS.
}

\author{
Joel Albino Rabaiolli ${ }^{1}$ \\ Alecsandra dos Santos Cunha ${ }^{2}$ \\ Vera Maria Favila Miorin ${ }^{3}$
}

Resumo:

A presente pesquisa analisa transformações do setor agrícola de Santa Maria - RS, perspectivas de desenvolvimento socioeconômico, tendo como objetivo principal compreender estas transformações que representam a categoria socioespacial denominada meio rural. Tais alterações são focadas na óptica da multifuncionalidade das propriedades familiares do meio rural. As expectativas sinalizam para novos papéis com importância no contexto do desenvolvimento contemporâneo para o meio rural. Acredita-se que é ampla a abrangência das atividades agrícolas e não agrícolas desenvolvidas no meio rural variando suas funções cuja identificação pode ser realizada pelas análises, interpretações e reflexões a respeito dos subsistemas, englobando seus fixos e fluxos.

Palavras-chave: Agricultura familiar, Multifuncionalidade, Meio rural, Propriedades familiares.

\section{MULTIFUNCIONAL FAMILY PROPERTIES IN THE RURAL CLASS IN DISTRICTS OF ARROIO GRANDE AND SÃO VALENTIM - SANTA MARIA/RS.}

\begin{abstract}
:
This research analyzes the transformations of agrarian sector of Santa Maria - RS, perspective of socioeconomic development, with the main objective of understand these transformations that represent the socio-spatial class called rural. These changes are focused on the optical properties of the multifunctional family of rural class. The expectations point to new roles that are important in the context of contemporary development to the rural class. It's believe that is ample the scope of agricultural and non-agricultural activities developed in the rural class

\footnotetext{
${ }^{1}$ Mestre em Geografia pelo Programa de Pós-Graduação em Geografia da Universidade Federal de Santa Maria. E-mail: joelrabaiolli@gmail.com.

${ }^{2}$ Doutoranda em Geografia pelo Programa de Pós-Graduação em Geografia da Universidade Federal de Santa Maria. Email: alecsandrascunha@gmail.com.

${ }^{3}$ Professora do Departamento de Geografia e do Programa de Pós-Graduação em Geografia da Universidade Federal de Santa Maria. E-mail: vmiorin.sma@terra.com.br.
} 
and there are several functions wich identification can be performed by analysis, interpretations and reflections about the subsystems, including its fixed and flows.

Key words: Familiar agriculture, Multifunctionality, Rural class, Familiar properties.

\section{PROPIEDADES FAMILIARES MULTIFUNCIONALES EN LAS ZONAS RURALES DE DISTRITOS ARROIO GRANDE Y SÃO VALENTIM - SANTA MARIA/RS}

\section{Resumen:}

Esta investigaciónanalizalatransformacióndel sector agrícola de Santa Maria - RS, las perspectivas de desarrollo socioeconómico, conel objetivo principal de comprender estas transformaciones que representan a lacategoríasocioespacialllamadamediorural. Tales cambios se centranenla perspectiva de lamultifuncionalidad de lasexplotacionesfamiliares de las zonas rurales. Las expectativas de señal para lasnuevas funciones de importanciaenel contexto deldesarrollocontemporáneo de las zonas rurales. Se cree de que existe un amplio campo de actividades agrícolas y no agrícolasenlas zonas rurales que van sus funciones cuyaidentificaciónpuederealizarse mediante unanálisis, interpretaciones y reflexiones sobre los subsistemas, cubriendosufijo y flujos.

Palabras clave: agricultura familiar, lamultifuncionalidad, rural, propiedadesfamiliares.

\section{INTRODUÇÃO}

A dificuldade no emprego de tecnologias em propriedades de produção de pequeno porte, como é o caso da exploração familiar que corresponde a uma unidade de produção agrícola na qual propriedade e trabalho estão intimamente ligados à família (LAMARCHE, 1993, p.15), seja por problemas financeiros ou pelas características das propriedades, é um dos fatores que diferenciam o modo de produção da agricultura familiar dos demais modos de produção voltados especificamente para o mercado interno e/ou externo. A busca por novas oportunidades para a manutenção das pequenas propriedades, obtenção de trabalho, renda e condições adequadas de vida traduz as dinâmicas promovidas e atuantes no meio rural.O desenvolvimento rural em áreas de predomínio de propriedades de produção de pequeno porte com a exploração familiar advém das ações instituídas na busca da sobrevivência familiar consentindo, como alternativa, os ganhos econômicos e a preservação do meio ambiente. Decorrente das ações estabelecidas, resulta a diversidade de oferta de produtos in natura e/ou transformados cuja qualidade e natureza advêm de saberes tradicionais, que os diferenciam 
dos produtos industrializados em larga escala, e podem ser considerados como alternativas eficazes à manutenção da pequena propriedade, definida por Lamarche (1993).

Essas formas de produção instituídas nas unidades, até então meramente agrícolas com exploração familiar, diversificam o sistema produtivo e colocam no mercado uma variedade significativa de produtos que se definem por sua qualidade, sabores, diversidade de produção e se caracterizam como um retorno às antigas formas de produzir, partindo dos saberes culturais inerentes aos diversos grupos sociais. Esta diversidade de produção determina a variedade de mercadorias em oferta e se confronta com os produtos oriundos de processos advindos da intensa industrialização, que obedecem à dinâmica do capitalismo e disputam os mesmos mercados, porém a exploração familiar tem suas vantagens ao trabalhar com processos naturais de produção e de transformação.

Deve-se levar em conta que a maioria destas unidades de produção de pequeno porte com exploração familiar localiza-se em paisagens únicas, contendo uma tradição no modo de vida e de produção, permitindo que se explorem também estas qualidades paisagísticas e culturais em um momento em que a sociedade busca a paz, o sossego, o bem estar, o ar puro e, principalmente, o contato com a natureza, constituindo o que alguns denominam de capital social e natural (BAQUERO, 2003; COSTA, 2003; REIS, 2003; RENNÓ, 2003; VAIDIVIESO, 2003).

Devido a esse conjunto de elementos apresentados, entende-se que a procura destas particularidades, específicas do meio rural, tem permitido o retorno do homem ao campo para desfrutar a curto, médio ou longo prazo, destes ambientes aprazíveis (CARNEIRO; MALUF, 2003; MULLER, 2007; WANDERLEY, 2003). Entretanto, a sustentabilidade das pequenas propriedades de exploração familiar, destacando-se o "agricultor familiar" requer, do grupo familiar, contínuas estratégias para que haja comprometimento na manutenção e sustentação da produção, do produto e do próprio ambiente.

A qualidade de vida hoje observada nas pequenas propriedades rurais de Santa Maria RS resulta da diversificação da produção alimentar, obtenção de produtos com qualidade, geração de renda adicional à produção agrícola, conservação e uso racional dos recursos naturais. A figura do agricultor familiar guarda em si o conjunto de técnicas, práticas econômicas, sociais e ambientais coerentes com a realidade do seu sistema de produção no qual a interação dos fatores permite explicar as distintas maneiras de atuação homem/natureza. 
O município de Santa Maria está localizado no centro do Estado do Rio Grande do Sul e se destaca por ser um polo regional, contendo uma população de 261.031 habitantes, distribuídos em $1779 \mathrm{Km}^{2}$ (IBGE, 2010). De acordo com a Fundação de Economia do Estado do Rio Grande do Sul (FEE, 2010) em torno de 248.347 habitantes vivem no meio urbano, junto à sede municipal, e 12.684 habitantes no meio rural, distribuídos nos distritos de São Valentim, Pains, Arroio Grande, Arroio do Só, Passo do Verde, Boca do Monte, Palma, Santa Flora e Santo Antão.

Ao se analisar os dados demográficos do IBGE, observa-se o intensivo e crescente aumento populacional no período compreendido entre os anos de 1910 a 2010, que fez com que Santa Maria despontasse como um dos mais populosos municípios do Estado do Rio Grande do Sul. O aumento populacional trouxe mercado para a produção agrícola local e regional, dinamizando os distritos, aperfeiçoando-os e os adequando para garantir espaço no crescente mercado consumidor. Surgiram inúmeras agroindústrias familiares no meio rural, que agregaram valor à produção através da transformação da matéria prima oriunda, principalmente, da agricultura familiar e resultando em uma produção diversificada.

Diante das características assumidas, social e economicamente, pela agricultura familiar, atualmente aguça a ciência geográfica o interesse em desvendar estas novas atividades que reorganizam o meio rural em outro nível de relações permitindo aos pequenos produtores novas oportunidades de produção e renda.

A determinação da multifuncionalidade possibilita reconhecer as múltiplas funções, suas transformações e suas complexas dinâmicas estabelecidas nos espaços que servem de "palco" a estas relações, estabelecidas pelos homens entre si e no espaço. Para o entendimento destas dinâmicas e de suas relações deve-se dar atenção às representações sociais e econômicas que instigam as ações humanas, entendendo que elas decorrem de processos sociais desenvolvidos no meio rural e, por vezes, advindos do urbano que instiga uma ação sustentável nas relações de oferta e procura da produção.

Seguindo esta linha de pensamento, entende-se que se faz necessário reconhecer através do estudo, da avaliação e interpretação, as dinâmicas sociais atuantes na categoria socioespacial meio rural, assim como a complexidade de suas ações estabelecidas nas relações com o urbano que lhe serve de mercado de consumo. 


\section{PROCEDIMENTOS METODOLÓGICOS}

Os estudos das interferências sofridas pelo meio rural permitem visualizar as mudanças no modo de produção agrícola. Para tais estudos, da categoria geográfica meio rural, vale-se da metodologia sistêmica, originada na Teoria Geral dos Sistemas (TGS), trabalhada por Bertalanffy (1975), através das ideias de sistema de Morin (2005), e da periodização do tempo/espaço com base no período Técnico-Científico-Informacional, de Santos (1997).

Pode-se dizer que a Ciência passou a trabalhar com complexos, totalidades ou sistemas em todos os seus campos do conhecimento, implicando na reorientação do pensamento científico. Para tanto, na Geografia, que se assenta na ampla relação homem/natureza,foi necessário romper a ideia de simplicidade, de racionalidade ordenada e de estudo fracionado/estudo geral para uma concepção de complexidade, na qual os vários campos da ciência, também, passam a se integrarem a um nível de aprofundamento segundo determinado grau de relações a serem analisadas, pois segundo Bertalanffy (1975), nenhum campo da Ciência hoje se apresenta isolado ou fechado em si mesmo.

A teoria dos sistemas, segundo Morin (2005), abrange um campo vasto em que qualquer realidade conhecida pode ser entendida como um sistema, ou seja, é uma associação de diferentes elementos combinados. Um sistema possui seu grau de complexidade e, sua integralidade não pode ser reduzida à soma de suas partes constituintes. Ao se analisar um sistema, a lógica desenvolvida tende a ser reducionista, isto é, decompõe o todo em partes, porém a análise sistêmica não pode permitir tal ocorrência, uma vez que o funcionamento de um sistema não depende só dos elementos que o compõem, mas também da interrelação entre estes elementos, pois poderá ocorrer um erro interpretativo, que é o de ter o todo como a soma das partes e não o todo constituído por todas as suas partes.

Conforme Santos (1997), a abordagem sistêmica permite compreender o período Técnico-Científico-Informacional, o homem que se organiza em sociedade e, igualmente, os arranjos que determinam o espaço, além da concepção das mudanças espaciais oriundas de sua utilização. Os elementos que constituem a natureza estão organizados em torno da estrutura, forma e função, passando por sucessivos processos. Decorrente desta estrutura, se dá a identificação e diferenciação de cada sistema, podendo haver semelhanças e especificidades. 
A presença de um sistema indica a existência de atividades decorrentes de um processo interligado. O meio rural caracteriza-se como um sistema complexo, composto por subsistemas passíveis de identificação. Pode-se afirmar que há uma relação de complementaridade e dependência, ao analisar o Sistema de Produção Agrícola em estudo, no qual os subsistemas e elementos que os compõem possuem particularidades, sendo responsáveis por variações internas no sistema.

Assim, a categoria meio rural assume a posição de sistema contendo suas formas, funções, processos e estruturas que se alteram dada a fluidez do espaço submetido à irradiação do meio técnico-científico-informacional com a globalização (SANTOS; SILVEIRA, 2001, p.53). Destaca-se que uma das características do presente período histórico é a necessidade de criar condições para a vida, vivências e circulação do produto, das mercadorias, dos homens, do dinheiro, da informação, da técnica e outras mais, permitindo que se reconheça a presença da fluidez nas mais distintas espacialidades.

Dada a importância de se conhecer densamente estas teorias, para que sua compreensão possa abrir os caminhos para o entendimento do meio rural enquanto sistema que se baseia em estruturas, formas e funções, se torna essencial uma minuciosa revisão bibliográfica sobre tais temas. Por isso, o presente trabalho foi desenvolvido a partir de etapas específicas, sendo a primeira delas, a revisão bibliográfica. Isto porque conformeLuna (1999), a pesquisa bibliográfica refere-se a um apanhado sobre os trabalhos científicos que já foram realizados sobre o tema de interesse e que oferecem informações relevantes que servem de arcabouço teórico para a construção de novos conhecimentos.

Outra etapa de desenvolvimento do trabalho foi a observação em campo e o reconhecimento da área de estudo, sendo estas ações uma das formas de coleta de informações, como reconhece Lakatosetal. (1996). No primeiro contato é possível identificar e obter provas a respeito dos objetivos, que em muitos casos, mesmo inconscientemente, refletem a orientação do comportamento espacial. Neste momento, há o contato direto do pesquisador com a realidade estudada, no qual é possível observar e registrar fatos desta realidade.

A partir deste primeiro contato, optou-se por entrevistas semiestruturadas, que combinam perguntas abertas e fechadas, dando possibilidade ao entrevistado falar sobre o tema proposto e, assim, obterem-se informações relevantes. Este tipo de entrevista segue 
como uma conversa informal, porém no momento que o assunto for de grande valia a conversa é explorada por meio de perguntas adicionais.

Portanto, a partir das argumentações expostas para o desenvolvimento desta investigação científica houve, em um primeiro momento, a realização da pesquisa bibliográfica e, na sequência, realizou-se o levantamento de dados, fornecidos por órgão oficiais, como por exemplo, IBGE. Com a obtenção destas informações, passou-se para as observações de campo buscando reconhecer e desenvolver reflexões a respeito das informações inerentes aos fenômenos e seus dados coletados.

As observações de campo referem-se a visitas nos pontos de venda dos produtos provenientes do meio rural, como: feiras, quiosques e pontos de venda do Cooesperança ${ }^{4}$, além da visita nas propriedades familiares dos distritos selecionados.

A coleta de dados secundários foi obtida junto às instituições públicas - prefeitura Municipal e subprefeituras distritais, órgãos governamentais como FEE e IBGE. E os dados primários foram coletados em trabalho de campo realizado nos distritos do município com predominância da agricultura familiar. Por meio de entrevistas semiestruturadas obtiveram-se informações qualitativas, em campo através da aplicação de um questionário para avaliação e interpretação das atividades e das transformações da categoria socioespacial meio rural, que serviram de apoio às análises juntamente com os dados do censo agropecuário, IBGE (2006), para o município de Santa Maria. Deste modo foi possível determinar os fixos e fluxos existentes nas espacialidades analisadas, bem como conhecer as dinâmicas que envolvem a agricultura familiar e que possibilitam o seu desenvolvimento no alcance da multifuncionalidade de suas ações.

O questionário para avaliação e interpretação das atividades e das transformaçõescompreende o bloco de variáveis que, por meio de seus atributos, prestam as informações necessárias à mensuração da presença e quantidade de fixos e de fluxos existentes nas unidades de produção, obedecendo aos objetivos propostos na pesquisa, a saber.

\footnotetext{
4“A TEIA ESPERANÇA, é a REDE DOS EMPREENDIMENTOS SOLIDÁRIOS Associados ao PROJETO ESPERANÇA/COOESPERANÇA foi criada no dia 14 de janeiro de 2003, com o objetivo principal de articular os Empreendimentos Solidários, associados ao PROJETO ESPERANÇA/COOESPERANÇA, para uma maior articulação dos produtores (as) e consumidores (as) para motivar o Comércio Justo, o Consumo Ético e Solidário através dos pontos de Comercialização Direta dos Municípios da região Centro e a articulação dos Empreendimentos entre si." (Site Oficial Projeto Cooesperança). Disponível em: http://www.esperancacooesperanca.org/cooesperana. Acesso em: 30 set. 2016.
} 
Variável 1 - Identificação do estabelecimento. Esta variável procura, por meio dos atributos, identificar a localização do estabelecimento no seu respectivo distrito e a distância média em relação à sede do município; o número de pessoas componentes da família, bem como daqueles que formam a força de trabalho. Os atributos referentes: ao tempo de residência no local, procurando averiguar se é um estabelecimento recente ou não; à descendência de seus moradores, pois se trata de uma formação multicultural que configura o conjunto demográfico do município de Santa Maria; por fim, destacou-se o atributo sobre a presença de aposentados entre os membros da família.

Variável 2 - Infraestrutura da propriedade. Nesta variável os atributos selecionados para o questionário indagavam sobre: as condições dos fixos que determinam a infraestrutura da propriedade; a presença da casa; tipo de construção e número de cômodos; condições de conforto e comunicação, como luz elétrica, água encanada, telefonia e internet; presença de visitantes, tempo de duração e período das visitas; existência de rodovias e acessibilidade com relação à moradia; serviço de transporte coletivo e acesso a ele; existência de meio de transporte particular da família.

Variável 3 - Estrutura da propriedade. Esta variável teve como atributos atender à situação da propriedade no que diz respeito: se a propriedade é própria, arrendada ou outra forma de uso; dimensão e se houve aumento ou diminuição de sua área, nos últimos anos. Deste modo, buscou-se esclarecimentos sobre a presença ou não de transformações ocorridas e referentes à estrutura fundiária.

Variável 4 - Produção e operacionalização das atividades nos estabelecimentos. Os atributos para esta variável envolvem inúmeras indagações que respondem diretamente à presença da multifuncionalidade, iniciando com o uso da propriedade e o número de estabelecimentos que ela possui e diferenciando as atividades agrícolas daquelas não agrícolas. Após, investigou-se a data em que tiveram início tais atividades, como estabelecimentos da propriedade; origem da renda principal; atividades que compõem o montante mais significativo da renda; razão da presença de atividades agrícolas e as motivações que determinam sua continuidade. Indagações semelhantes foram realizadas sobre as atividades não agrícolas. Em continuidade, indagaram-se os motivos que levam a propriedade a manter estabelecimentos com atividades não agrícolas; perspectivas futuras destas atividades; presença ou não da transformação artesanal de produtos e quais seriam eles; perspectivas de futuro, desenvolvimento de novas atividades e a existência de artesanatos, 
independente de ser agrícola, ou seja, outro tipo de artesanato. Também compõem esta variável os atributos referentes às possibilidades de comercialização dos produtos; aceitação dos produtos e como o preço final é avaliado. Por fim, foram questionados os atributos referentes à presença ou não de atividades prestadoras de serviços como: lazer e turismo, e seu funcionamento.

Variável 5 - Tipos de relações cidade/campo. Nesta variável procurou-se conhecer os atributos referentes à: frequência de pessoas e o fluxo que promovem entre campo/cidade; finalidade destes fluxos, indagando-se em cada propriedade e em cada um de seus estabelecimentos a presença e intensidade de tais fluxos. Além disso, também, procurou-se conhecer os atributos referentes à frequência com que os membros da família vão à cidade e o que fazem nela.

Destaca-se que todas as informações foram significativamente relevantes e contribuíram para análise, avaliação, interpretação, bem como, para identificação da ocorrência de transformações das atividades que compõem a agricultura familiar no meio rural dos distritos objeto de estudo nesta pesquisa sobre multifuncionalidade. Cada etapa da pesquisa teve fundamental importância para o alcance dos objetivos. No entanto, cabe destacar que o conjunto de dados que foram analisados nesta pesquisa não permite generalizações e não se aplica em outros municípios com características semelhantes, por serem únicos a cada espacialidade em questão.

\section{O ADVENTO DE DIVERSAS RURALIDADES}

Novos caminhos se desenvolvem com perspectivas de evolução social e econômica do meio rural destituindo a oposição formada sobre a descontinuidade entre o rural e o urbano (campo-cidade). Os estudos, em seu avanço, mostram que, assim como o urbano, o rural tem características próprias e marcantes, mas em nenhum momento ligam-no a um cenário de atraso ou de escassez, pois estas especificidades atribuem valor ao meio rural ao mesmo tempo em que o distinguem do urbano. $\mathrm{O}$ modo de ser dos habitantes do meio rural passa a ser entendido, a partir do final do século XX, como parte definidora deste espaço no qual a agricultura influencia na organização social marcando esta espacialidade por uma desconcentrada densidade demográfica, guardando uma forte e específica relação com a natureza, como é referido em Carneiro et al. (2012). 
Portanto, em referência às especificidades das espacialidades rurais se relacionarem mais intensamente com a natureza deve-se à presença de alguns elementos fundamentais, que favorecem estes contatos dos habitantes locais com o meio natural de maneira mais intensa e imediata, quando se comparando com as relações dos habitantes dos centros urbanos. Contribuem para estas relações outros elementos importantes como a presença de áreas não densamente povoadas, nas quais não há a influência direta das cidades, mas apenas a representação junto à produção rural, de alguma das economias urbanas, como, por exemplo, cooperativas, laticínio ou frigorífico e, até mesmo, agências bancárias.

As dinâmicas atuantes no meio rural exibem um novo rumo no qual as tendências previstas do desaparecimento das áreas rurais, devido à expansão do urbano, não se confirmam bem como o seu enfraquecimento social, econômico e cultural. Consequentemente, a revitalização social e econômica observada no meio rural não significa o abandono das práticas agrícolas e nem se trata de urbanizar o rural, mas sim de permitir uma aproximação dos padrões de vida do rural com o urbano.

Para Carneiro et al. (2012), o crescimento populacional nas áreas rurais pode estar ligado ao aumento da capacidade produtiva das indústrias urbanas que utilizam menos mão de obra, devido ao emprego de tecnologias que melhoraram a eficiência e diminuíram os custos com a produção, obrigando a população, que esteve direta ou indiretamente ligada ao êxodo rural, com menos preparação técnica a atender as necessidades do mercado, a voltar ao campo. Por outro lado, diferente de Carneiro et al. (2012), acredita-se que a volta ao campo se deve às novas perspectivas de produção baseadas não apenas nas atividades agrícolas, mas no incremento de atividades não agrícolas, capazes de aumentar a renda familiar e de oferecer um modo de vida saudável que a cidade perdeu.

No denominado Novo Rural, o agricultor e sua família assumem papéis diferenciados, modificando a estrutura produtiva que antes estava calcada apenas em atividades agropastoris, no que concerne à produção. Silva (1997) concorda que a presença característica do homem no meio rural se deve às novas formas de trabalho. Ele não é mais apenas um agricultor ou um pecuarista, agora há uma combinação de atividades agropecuárias com outras atividades não agrícolas, que se desenvolvem não somente na propriedade, mas também fora dela, seja nos ramos tradicionais da indústria ou em novas atividades que vêm ganhando espaço no meio rural como lazer, turismo, conservação da natureza, moradia e prestação de serviços 
pessoais, entre outras. Com isto, deduz-se que o perfil do setor rural deve ser analisado segundo a produção, circulação e consumo.

Em Schneider (1999) observa-se que o uso da terminologia pluriatividade, como um conceito que procura analisar a unidade de produção e reprodução, nem sempre estaria baseada apenas nas atividades agrícolas e pastoris, mas na incorporação de outras atividades envolvendo os membros da família, porém voltados ao aumento de renda. Esta conceituação também infere que o termo pluriatividade contém o entendimento de aumento de renda devido à diversidade de atividades que ocupam, muitas vezes, as horas de ócio. Buscando harmonizar esta terminologia com as atividades existentes no meio rural, observa-se que elas remetem à presença de um fenômeno no qual os componentes de uma unidade produtiva familiar executam diversas atividades como objetivo de obter renda.

Pode-se dizer que a pluriatividade no meio rural também decorre do resgate daqueles valores histórico-culturais, no momento em que se buscava uma produção mais sustentável aos produtores familiares, proprietários de pequenas áreas e carentes de renda para o sustento e manutenção familiar. Estas novas atividades contavam com o auxílio dos membros da família, mas, inicialmente, eles não acreditavam no interesse que o mercado urbano teria por este tipo de produtos que o rural lhes oferecia. Ao se aliar o social ao econômico na tentativa de diversificar, houve a conquista de mercados alcançando qualidade de vida, preservando os recursos naturais e obtendo renda suficiente às famílias que vivem neste rural. Destaca-se que as novas atividades e o resgate das antigas tradições potencializam o rural permitindo que ele alcance evidência na reconstrução de novos espaços de vida social.

Entende-se que as ruralidades são compostas por objetos, ações e representações peculiares do rural, com destaque para as representações e identidades dos indivíduos e grupos sociais, conforme coloca Candiottoet al. (2008). Para o autor, a formação de ruralidades é um fenômeno mundial, resultante da presença de arranjos caracterizadores do capital social e identificadores do desenvolvimento rural. A partir das ideias do autor entendese que a presença de ruralidades pode identificar uma escala variável de funcionalidades, como, por exemplo, artesanatos provenientes de saberes tradicionais. Estas, por sua vez, podem ser identificadas como as novas funções que surgem no meio rural alterando suas estruturas.

Assim, pode-se considerar que o desenvolvimento no meio rural não consiste apenas, e nem se fundamenta, na conquista da competitividade dos segmentos produtivos e em sua 
variedade, mas sim na dinâmica determinada pela velocidade do tempo de adoção da tecnologia pelo grupo social em sua espacialidade de vida. O desenvolvimento no meio rural tem suas bases na difusão tecnológica e informacional auxiliada pela capacidade de comunicação do produtor familiar. Este, por sua vez, quando motivado, tende a buscar o acesso a equipamentos capazes de aproximá-lo a um contexto social mais amplo, ou seja, regional, nacional ou internacional. Deste modo, as urbanidades que lhes são próximas permitem-lhe incorporar tecnologias urbanas como: televisão, computador e telefonia celular para si e seus familiares.

Por sua vez, Silva (2001) compreende que o desenvolvimento rural não pode ocorrer por meio de uma noção reducionista, pois o verdadeiro desenvolvimento só se efetiva através da criação de novas oportunidades, com ampla abrangência. Portanto, sua concepção está relacionada a diversos fatores, os quais possuem desdobramentos e requerem distintas análises, sem generalizações que possam intervir na tradicional abordagem dicotômica de rural-urbano ou campo-cidade.

Os autores, em seus entendimentos, chamam a atenção para alguns elementos que servem como base para a compreensão do desenvolvimento rural. Veiga (2001), por exemplo, relaciona o desenvolvimento rural à diversificação produtiva e à pluriatividade, pelo aumento da produtividade. Conforme Silva (2001), o termo desenvolvimento rural não pode, simplesmente, ser associado à diversificação produtiva como forma de inclusão do agricultor familiar. Contudo, Veiga e Silva concordam que o essencial para uma estratégia de desenvolvimento para as áreas rurais (e também para as urbanas) deve estar relacionado ao combate à pobreza por meio da criação de novas oportunidades e não simplesmente por meio das políticas compensatórias.

Entende-se que o desenvolvimento rural é um conceito espacial e de várias áreas do conhecimento, sendo que a agricultura faz parte dele. Contudo, esse conceito repousa sobre três grandes funções indissociáveis: a função de produzir bens e serviços (econômica), a função de gestão do meio ambiente (função ecológica) e a função de ator do mundo rural (função social). Essa multifuncionalidade da agricultura provém do fato de que os sistemas agrícolas estão em interação permanente com os ecossistemas contíguos e com a sociedade humana pelo mercado e pelas relações de proximidade.

Cresce no mundo a discussão e a necessidade da revalorização de um rural multifuncional, exigindo um novo olhar sobre as populações rurais e as funções destas 
espacialidades. Abramovay (2000), já afirmavaque é necessário buscar um equilíbrio entre as funções produtivas clássicas do campo em sua lógica de oferta, bem como, das novas funções (residenciais, recreativas, ambientais, e outras) que contribuem para transformá-lo em espaço de consumo.

As múltiplas funções desenvolvidas pelos agricultores familiares, bem como dos demais atores sociais que atuam no meio rural, passam a ter relevância e a serem percebidas como algo moderno e adequado aos novos tempos da valorização do rural. Conforme Hervieu (1997), a agricultura deve ser entendida como uma profissão, assim como as demais, e os agricultores devem buscar alternativas capazes de assegurar seu espaço. Portanto, destaca-se o importante papel da produção de caráter multifuncional, a ser desenvolvido no meio rural, que é capaz de influenciar positivamente a sociedade por meio de suas funções, que vão além do binômio agropecuário.

As noções de ruralidade, pluriatividade e multifuncionalidade têm sido frequentemente mencionadas nos debates sobre as transformações recentes no meio rural e em novas abordagens que levam em conta o debate técnico e político dos termos. Nas ciências sociais, por exemplo, estes termos satisfazem as necessidades econômicas, como também as culturais e sociais.

Para Carneiro e Maluf (2003), a noção de multifuncionalidade rompe com o enfoque setorial e amplia as funções sociais conferidas à agricultura, deixando de ser entendida apenas como produtora de bens agrícolas para se tornar responsável pela conservação dos recursos naturais (água, solos, biodiversidade e outros), do patrimônio natural (paisagens) e pela qualidade dos alimentos.Trabalhar a multifuncionalidade supõe a reprodução sociocultural definida. Para a pluriatividade é reservado o entendimento de que o produtor agricultor é movido exclusivamente pela sobrevivência e pela produção. Porém, segundo Carneiro (1996), ao se considerar o agricultor como um ser social de múltiplas inserções e sendo ele um sujeito com desejos orientados por valores, que não são apenas os da lógica econômica, incorre a observação de que a produção familiar ou agricultura familiar não é somente vista pela perspectiva da produção.

De acordo com a lógica do contexto desenvolvido por Carneiro (1996), não se pode negar a visão economicista do produtor familiar ou de suas atividades familiares desenvolvidas, pois ao poupar seus recursos naturais ele está conservando seus bens de produção que não perdem o seu valor econômico de mercado, pelo contrário, ele estará 
valorizando os recursos da sua paisagem natural, cujo valor é inestimável.Deste modo, considera-se que a inovação de funções conduz à direção de uma visão integradora das esferas social, econômica e, principalmente, ambiental (considerando a biodiversidade das paisagens rurais) ao se analisar os papéis das atividades da agricultura, bem como da participação das famílias na espacialidade rural.

Nessa linha de pensamento, é possível alcançar a ideia de que a terminologia multifuncionalidade guarda em si o modelo da intensidade produtiva, tanto no agro como no pastoril, e que a unidade de agricultura familiar poderá se caracterizar como de produção intensiva. Assim, ela estaria cumprindo as funções requeridas pelo modo de produção voltado para a diversidade e sustentação no mercado, bem como de conservação dos recursos naturais.

Pode-se afirmar que a multifuncionalidade procura retomar a importância das contribuições funcionais, econômicas e de permanência do modo de vida da agricultura familiar nas dinâmicas econômicas, sociais e culturais, contribuições essas que, aliás, já faziam parte da prática camponesa e que foram inibidas pelo modelo produtivista, no pensamento de Carneiro, (2002).

Carneiro (2002), aponta para uma nova configuração das espacialidades rurais, nas quais se registram transformações do campo em espaço de lazer ou mesmo de residência principal para integrantes de camadas médias da população urbana. Esta busca, por parte dos habitantes das cidades, de um contato mais frequente e próximo com a natureza introduz mudanças nos hábitos e práticas de vida das pequenas localidades.Essas novas visões, colocadas como funções diferenciadas, que o rural desempenha e ou venha a desempenhar depende, significativamente, da importância dada à paisagem. Quanto mais valores ambientais, sociais e infraestrutura acumular, maior grau de ressignificações ocorrerão neste meio, de modo a permitir o uso da terminologia ruralidades como sendo uma nova representação do rural. Da mesma maneira como se analisam as formas no movimento da sociedade, as suas funções, além de seus processos geradores, também é possível analisar as ruralidades e observar nelas o movimento do ser social e suas ações na natureza alterando a espacialidade.

Normalmente, a pluriatividade e a multifuncionalidade destacam-se como atividades que caracterizam os espaços de vida "pacatos" das populações em novos movimentos dinâmicos. As mudanças de espaços pouco dinâmicos para mais dinâmicos, no meio rural, é o 
que chama atenção e desafia a compreensão do que realmente está acontecendo nestes ambientes de vida social.

Tudo isso traz importantes significados para esta categoria de análise geográfica, uma vez que o meio rural passou a ser observado, analisado, interpretado e questionado como nunca teria sido. Hoje, os estudos a respeito desta categoria da geografia perseguem muitos caminhos, ora valorizando uma ou outra temática, determinadoras de importantes revelações a respeito do comportamento humano, da produção, da história, da paisagem e da cultura de um lugar.

Os lugares que guardam sua originalidade ganham valor frente à degradação presente no meio urbano. Isto teria contribuído para chamar a atenção sobre a formação e existência de capital social que o rural possui e serve como base valorativa para o desenvolvimento rural, antes pouco compreendido pelo meio urbano.

\section{RESULTADOS DO COMPORTAMENTO DA AGRICULTURA FAMILIAR}

Como resultado das visitas no campo para a coleta das informações consideradas de ordem qualitativa que serviram de apoio às análises, as medidas obtidas através das informações inerentes aos atributos das variáveis permitiram identificar que: a variável 1, ao tratar da identificação do estabelecimento, nos diz que a distância média dos estabelecimentos dos distritos (Arroio Grande e São Valentim) em relação à sede municipal varia de menos de cinco a $30 \mathrm{~km}$ de distância, sendo que a maior incidência de estabelecimentos está situada em menos de 10 até $20 \mathrm{~km}$. Quanto ao número de pessoas que compõem os estabelecimentos há uma grande incidência de duas a quatro pessoas. Deste modo, a força de trabalho disponível nos estabelecimentos é pequena, permitindo identificar que ela varia entre duas a três pessoas.

Por outro lado, esta baixa ocupação dos estabelecimentos, quanto ao número de pessoas, permitiu identificar a existência de estabelecimentos sobre imóveis, de certo modo antigos, que datam do período da colonização no sul brasileiro, por descendência os atuais proprietários residem no lugar há um longo período e desenvolvem há mais de 25 anos seus estabelecimentos. Estes indivíduos são descendentes de imigrantes, na sua significativa maioria, de origem italiana e espanhola. Salienta-se que, normalmente, em cada casa de um dos estabelecimentos há a presença de aposentados, pelo menos uma pessoa ocupa esta condição. 
A variável 2, ao tratar da infraestrutura da propriedade, foi possível identificar as características da moradia. Em sua grande maioria, as residências são de alvenaria e possuem de seis a 14 cômodos, sendo que predominam as casas com sete cômodos. Há energia elétrica e água encanada em todas as propriedades, assim como o serviço de telefonia, porém algumas delas possuem apenas telefonia móvel, mas predomina a existência de ambos os serviços, móvel e fixo. $\mathrm{O}$ acesso à rede mundial de computadores está presente em grande parte das propriedades, aproximadamente, $80 \%$ delas.

O acesso das propriedades até as rodovias é diverso, sendo mais desenvolvido no distrito de Arroio Grande. As propriedades são próximas à rodovia principal (RS-304) e, na maior parte dos casos analisados, não ultrapassa a distância de 200 metros, porém, algumas propriedades estão situadas a até dois km.

Destaca-se a presença de serviço de transporte coletivo de forma regular. A distância de acesso das propriedades até os pontos de parada dos coletivos varia de 50 metros a dois km, mas, na maior parte dos casos, esta distância não ultrapassa 200 metros. Outra forma de deslocamento dos moradores das localidades ocorre por meio de veículos particulares presentes em quase todas as propriedades.

A variável 3 refere-se à estrutura da propriedade, no que diz respeito a sua situação. Existem imóveis próprios, arrendados e cedidos, mas o número de imóveis próprios atinge percentual acima de $75 \%$, pois a ocupação das áreas destes distritos provém de mais de 100 anos. O produtor que arrenda ou tem terras cedidas é também proprietário de uma parte de terras e, esta condição de arrendatário ou cedência, ocorre por necessidade de aumento de área produtiva.

A variável 4, referente à produção e operacionalização das atividades nos estabelecimentos, permitiu verificar quais são estas atividades, quando surgiram e como são operacionalizadas as atividades agrícolas e não agrícolas. Também se procurou, em um primeiro momento, identificar os fluxos que derivam das ações produtivas.

Destaca-se que há significativa predominância de ambas as atividades (agrícola e não agrícola) e que elas ocorrem hálongo tempo, contrariando o que se pensava anteriormente, que as atividades agrícolas tivessem dado início às atividades não agrícolas. Contudo, verificou-se que esta hipótese não se sustenta, uma vez que ocorrem atividades agrícolas iniciadas há mais de 50 anos, como também aquelas que tiveram início há 10 anos. O mesmo ocorre com as atividades não agrícolas. 
Diante dessa variação de tempo de início das atividades, indagou-se sobre a origem da renda, constatando-se que a renda principal é proveniente das atividades agrícolas. Quando se buscou caracterizar as atividades geradoras da renda agrícola, foram identificados os produtos hortifrutigranjeiros, o arroz, o milho e o criatório de animais. As atividades agrícolas são herança familiar, conhecimento passado de pai para filho. As atividades agrícolas também são mencionadas por muitos agricultores familiares por se constituírem em elementos de subsistência direta da família.

Quando indagados sobre a continuidade das atividades agrícolas foram unânimes em responder que desejam continuar com estas ações e, inclusive, muitos pensam em aumentar a área, investir em melhorias e em construções que favoreçam a produtividade. A geração de renda proveniente das atividades não agrícolas é, em parte, oriunda do processamento da produção agrícola, tais como vinagre e cachaça, queijo e do criatório.

Existem outras atividades como prestação de serviços de costura, confecção de doces e de salgados. Os produtores entendem que estas atividades não agrícolas se destinam ao aumento da renda familiar constituindo, muitas vezes, a própria subsistência familiar.

Ao manter o diálogo com os agricultores sobre estas atividades não agrícolas observou-se que eles pretendem continuar a sua execução. Constatou-se que a presença da transformação artesanal de alguns produtos é comum a um nível de significância superior a $70 \%$ dos estabelecimentos, isto ocorre em relação à mandioca, leite, frutas, mel, abóbora, cana-de-açúcar e ovos, entre outros.

Quando indagados sobre as pretensões de aumentar a produção artesanal, a maioria respondeu que não pretende, pois há falta de mão de obra e a área da propriedade/estabelecimento é limitada. Quando indagados sobre a diversificação da produção eles entendem na medida em que a produção agrícola diversifica também podem diversificar a produção artesanal e se for por necessidade da família, ela ocorrerá. Por outro lado, não há interesse dos agricultores familiares em implementar outras atividades. As atividades de artesanato como crochês, bordados, costuras, macramê, imãs de geladeira, são, geralmente, realizadas pelas mulheres. Contudo, constatou-se a existência de móveis artesanais, chapéus de palha, utensílios para pesca e trabalhos com couro realizados por homens.

A produção agrícola é comercializada no município de Santa Maria, dirigindo-se principalmente para feiras, engenhos, cooperativas, mercados e quitandas. Destaca-se, 
também, a destinação para merenda escolar (participação no Programa Nacional de Alimentação Escolar - PNAE). A produção não agrícola e o artesanato são colocados para venda nas feiras, mercados e quitandas, além de encomendas, que podem ser buscadas nas propriedades ou entregues diretamente ao consumidor.

A avaliação do preço final do produto, seja ele oriundo das atividades agrícolas ou não agrícolas e artesanais, resulta de alguns elementos como: valor da matéria prima, trabalho, tempo de trabalho e valor de mercado, identificando-se assim que os agricultores familiares são bem informados e valorizam suas atividades.

Por último, foi indagado se nas propriedades existem estabelecimentos de prestação de serviços como hotel/pousada, restaurante e espaços de lazer/esporte. Houve unanimidade na informação que estes tipos de prestação de serviços não existem nas propriedades familiares. Contudo, no distrito existem restaurantes, cujos proprietários são agricultores familiares, e os espaços para realização de esportes e lazer ocorrem nos balneários e nos centros comunitários.

A variável 5, referente aos tipos de relações cidade/campo, procurou indagar aos entrevistados sobre a existência e a frequência com que eles recebem pessoas provenientes da cidade, podendo-se compreender que as relações são diárias, identificando a normalidade do fluxo de pessoas que saem do campo para cidade e da cidade para o campo. Os que saem do campo para cidade vão estudar nela, fazer compras no comércio, buscar serviços de saúde e bancários, além de levar produtos para venda e as encomendas feitas pelos mercados, quitandas, pontos de vendas, cooperativas e em feiras, predominando as compras que os agricultores familiares necessitam no meio rural, bem como a venda de sua produção na cidade. Caracteriza-se, desta maneira, a relação campo/cidade. Por outro lado, identificou-se que diariamente ocorre a presença de pessoas da cidade que vão até os distritos estudados buscar produtos encomendados, quer da produção agrícola ou da produção não agrícola, como: feijão, mandioca, mel, ovos, hortifrutigranjeiros, flores, compotas, queijo, pães, cucas, salgados diversos, artesanatos, confecção de roupas, facas, embutidos, cachaça, vinho e produtos da gastronomia, como bolo de mandioca, agnolines (massa recheada para sopas), massas caseiras.

Por outro lado, o fluxo cidade/campo ocorre durante as festividades religiosas e as tradicionais, como festa da mandioca e jantar italiano, e em finais de semana, procurando lazer no campo e nos balneários, bem como a gastronomia diferenciada, as cantinas, os cafés 
coloniais que estes distritos oferecem aos moradores urbanos que buscam o meio rural nestas ocasiões.

\section{CONSIDERAÇÕES FINAIS}

As análises realizadas permitiram determinar a partir da categoria Meio Rural, no que diz respeito à agricultura familiar, como subsistemas fixos os elementos como: a terra, determinada pela área disponível para as atividades; a mão de obra familiar e a infraestrutura disponível, de acordo com as informações coletadas junto às propriedades familiares (casa, energia elétrica, água encanada, estradas, rodovias); os produtos das atividades agrícolas, não agrícolas e artesanais.

Por subsistemas fluxos considerou-se a presença de fluxos a partir da existência dos fixos identificados, por exemplo: telefonia, internet e rodovias que atuam como meios de comunicação entre o meio rural e meio urbano que lhe é próximo e a área geográfica onde está inserido. As boas condições como se apresentam os fixos refletem-se na qualidade dos fluxos e permite deduzir que a existência de transporte coletivo indica que as estradas apresentam boas condições de trafegabilidade e que as distâncias não são significativas entre as áreas produtivas, os centros de apoio comercial e prestação de serviços, entendidos pela frequência dos que vão do campo/cidade e cidade/campo.

Por outro lado, a intensa e diversificada circulação de mercadorias, igualmente, assegura que estas, na qualidade de fluxos, caracterizam o chamado meio rural como novo rural, pois ele se apresenta contendo uma diversificação de atividades e funções que permitem no momento reconhecê-lo como um "novo rural multifuncional". Podem ser observados como componentes dos Fixos: Presença de propriedades familiares, Presença de estabelecimentos, Famílias rurais, Mão de obra rural, Moradias, Energia elétrica, Água encanada, Telecomunicações, Transportes. Os Fluxos identificados na área de estudo: Deslocamento de pessoas, Comercialização da produção, Distribuição de gêneros alimentícios, Relações campo/cidade - cidade/campo, Prestação de serviços diversos e Circulação de informações.

Como resultado da presença da multifuncionalidade nos distritos analisados, pode-se dizer que eles ainda não desenvolvem alguns elementos comuns para serem considerados nesta condição, como o turismo rural e variadas atividades de lazer. Contudo, se reconhece plena capacidade e ações desempenhadas nas transformações da produção de origem agrícola, 
da agroindústria e de outras atividades não rurais que se desenvolvem no meio rural gerando renda e, assim, conservando as famílias e a própria agricultura familiar.

\section{REFERÊNCIAS}

ABRAMOVAY, R. Do setor ao território: funções e medidas da ruralidade no desenvolvimento contemporâneo. In: Interrelações entre as transformações demográficas e a agenda social. São Paulo: Instituto de Pesquisas Aplicadas - IPEA, USP, 2000.

BAQUERO, M. Construindo uma outra sociedade: o capital social na construção da política participativa no Brasil. Revista de Sociologia e Política, Curitiba, n. 21, p. 83-108, 2003.

BERTALANFFY, L. V. Teoria Geral dos Sistemas.2 ed. Petrópolis: Vozes, 1975.

CANDIOTTO, L. Z. P; CORRÊA, W. K. Ruralidades, urbanidades e a tecnicização do rural no contexto do debate cidade-campo.Campo Território: Revista de Geografia Agrária. n. 5, v. 3, p. 214-242, fev. 2008.

CARNEIRO, M. J. et al. Ruralidades Contemporâneas: modos de viver e pensar o rural na sociedade brasileira. Rio de Janeiro: MUAD X. FAPERJ, 2012.

CARNEIRO, M. J. Multifuncionalidade da agricultura e ruralidade: uma abordagem comparativa.Rio de Janeiro: CPDA/UFRRJ, 2002. (Textos para Discussão).

CARNEIRO, M.J. Pluriactivité: 1'hétérogénéitécachée.Cahiers

d'EconomieetSociologieRurales, 1996.

CARNEIRO, M. J; MALUF, R. Para além da produção: Multifuncionalidade e Agricultura Familiar. Rio de Janeiro: MAUAD, 2003.

COSTA, M. A. N. Sinergia e capital social na construção de políticas sociais: a favela da Mangueira no Rio de Janeiro. Revista de Sociologia e Política, Curitiba, n. 21, p. 147-163, 2003.

FEE. Fundação de Economia e Estatística. Dados Estatísticos. SEPLAG, 2010.

HERVIEU, B. Los campos del futuro. Madrid: Ed. MAPA, 1997.

IBGE - Instituto Brasileiro de Geografia e Estatística. Perfil dos Municípios. 2010.

Disponível em: http://cidades.ibge.gov.br/xtras/perfil.php?codmun=431690. Acesso em 20 mai. 2016.

IBGE - Instituto Brasileiro de Geografia e Estatística. Censo Agropecuário 2006. Disponível em: http://www.ibge.gov.br/home/estatistica/economia/agropecuaria/censoagro/. Acesso em 13 abr. 2016.

LAKATOS, E. M; MARCONI, M. A. Técnicas de pesquisa.3 ed. São Paulo: Editora Atlas, 1996.

LAMARCHE, H. Agricultura Familiar. v.1. Trad.: Tijiwa A. M. N. Campinas: Editora da UNICAMP, 1993. 
LUNA, S. V. Planejamento de pesquisa: uma introdução.2 edição. São Paulo: EDUC, 1999.

MORIN, E. Introdução ao pensamento complexo. Trad.: Eliane Lisboa. Porta Alegre: Sulina, 2005.

MULLER, J. M. Multifuncionalidade da agricultura e a agricultura familiar: a reconstrução dos espaços rurais em perspectiva. Anais...VII Congresso Brasileiro de Sistemas de Produção, de 4 a 6 de setembro de 2007, Fortaleza - CE.

REIS, B. Capital social e confiança: questões de teoria e método. Revista de Sociologia e Política, Curitiba, n. 21, p. 35-49, 2003.

RENNÓ, L. Estruturas de oportunidade política e engajamento em organizações da sociedade civil: um estudo comparado sobre a AméricaLatina. Revista de Sociologia e Política, Curitiba, n. 21, p. 71-82, 2003.

SANTOS, M. A natureza do espaço. São Paulo: HUCITEC, 1997.

SANTOS, M; SILVEIRA, M. L. O Brasil: território e sociedade no início do século XXI. Rio de Janeiro: Record, 2001.

SCHNEIDER, S. Agricultura familiar e industrialização: pluriatividade e descentralização industrial no Rio Grande do Sul. Porto Alegre: UFRGS, 1999.

SILVA, J. G. O novo rural brasileiro. Belo Horizonte: Nova economia, 1997.

SILVA, J. G. Quem precisa de uma estratégia de desenvolvimento? In: SILVA, J. G; VON DER WEID, J. M; BIANCHINI, V. O Brasil Rural precisa de uma Estratégia de

Desenvolvimento. Brasília: MDA/CNDRS/NEAD. Série textos para discussão nº 02, 2001.

VALDIVIESO, P. Capital social, crisis de la democracia y educaciónciudadana: la experiência chilena. Revista de Sociologia e Política, Curitiba, n. 21, p. 13-34, 2003.

VEIGA, J. E. O Brasil rural precisa de uma estratégia de desenvolvimento. Brasília: Convênio CNDRS, MDA, NEAD. Texto para Discussão nº 01, 2001.

WANDERLEY, M. N. B. Prefácio. In: Para além da produção: Multifuncionalidade e agricultura familiar. Rio de Janeiro, 2003.

Recebido em Outubro de 2016

Aprovado em Maio de 2017

Publicado em Agosto de 2017 